\title{
The effect of nutritional composition on the glycemic index and glycemic load values of selected Emirati foods
}

\author{
Ayesha S Al Dhaheri ${ }^{*}$, Asila K Al Ma'awali ${ }^{1}$, Louis C Laleye ${ }^{2}$, Sidiga A Washi ${ }^{1}$, Amjad H Jarrar ${ }^{1}$, \\ Fatima T Al Meqbaali ${ }^{1}$, Maysm N Mohamad ${ }^{1}$ and Emad M Masuadi ${ }^{3}$
}

\begin{abstract}
Background: Population-based studies have shown an association between health, food composition, and diets; therefore, data on the composition of traditional foods for meal planning, nutritional assessment, and clinical nutrition research to build up a relevant database are needed.

Methods: The objective of this study was to assess the effect of the nutritional composition of five commonly consumed traditional Emirati foods, Threed chicken, Marqoga, Gurus, Assidah, and Saqo, on the glycemic index (GI) and glycemic load $(\mathrm{GL})$ values. Fifteen healthy subjects aged between 18 and 25 years old participated in this study.

Results: The proximate analysis showed high amounts of protein in Gurus and Threed chicken and high-fiber content in Gurus. The carbohydrate percentages for the foods tested were as follows 54.4\% in Gurus, 23.4\% in Saqo, 21.1\% in Assidah, 13.3\% in Marqoga, and 12.3\% in Threed chicken. The corresponding Gl values were high: 71.7, 99.4, $99.2,84.6$, and 71.9 , respectively. The GL values of the foods tested were also considered high, varying from 35.85 to 49.7. The incremental increase in blood glucose was monitored and calculated for each food and when compared with the standard food (glucose) showed significant differences $(P<0.001)$ for all foods except Sago and Assidah at $30 \mathrm{~min}$, with similar responses at $45 \mathrm{~min}$. At $120 \mathrm{~min}$, no significant differences in blood glucose levels were observed $(P>0.05)$. The types of carbohydrate, different ingredients of foods, and cooking method used all contributed to the $\mathrm{Gl}$ value.

Conclusions: The Gl value of traditional foods can be modified through altering the ingredients, cooking method, or the portion size served. This data will help to inform decisions on the diet and health of consumers in the UAE.
\end{abstract}

Keywords: Glycemic index, Glycemic load, Traditional foods, Emirati foods, University students, United Arab Emirates (UAE)

\section{Background}

The incidence of diabetes is dramatically increasing worldwide, reflecting current lifestyle trends, characterized by calorific abundance in foods and low physical activity. The incidence of type 2 diabetes mellitus (T2DM) not only influences the individual's health but also causes an economic loss to society, with increased health-care costs. Obesity is a well-known major independent risk

\footnotetext{
* Correspondence: ayesha_aldhaheri@uaeu.ac.ae

${ }^{1}$ Nutrition and Health Department, College of Food and Agriculture, United Arab Emirates University, Al Ain, United Arab Emirates

Full list of author information is available at the end of the article
}

factor for developing T2DM [1] and is strongly correlated with insulin-sensitivity reduction, especially in people with excess abdominal fat distribution and physical inactivity [2].

In general, insulin resistance increases with increased body fat mass (FM), and this often exists in patients long before their diagnosis with T2DM. It has been estimated that more than 135 million people globally have T2DM, particularly in the United States, with more than 20 million diabetic patients [3]. The United Arab Emirates (UAE) has been ranked by the International Diabetes Federation (IDF) as having the 15th highest prevalence 
rate of T2DM in the world [4]. Owing to the severity of this disease, interest in the underlying mechanism has become increasingly important [5]. However, the high prevalence of diabetes in the UAE could be related to the individual's lifestyle choices, with the main reason being their dietary habits. Positive lifestyle modification and preventive measures are needed to decrease the rapid growth of this problem. Several alternative therapies have been identified such as surgical, physical, and dietary therapy and low-carbohydrate, high-fiber, lowcalorie, and low-glycemic index (GI) diets.

The GI concept has clinically important benefits for preventing, managing, and treating a number of chronic diseases such as diabetes, cardiovascular disease (CVD), and some forms of cancer and obesity [6]. Foods that are classified as low GI provide a better response to postprandial glucose, causing a slight increase in circulating levels of insulin and gastrointestinal hormones. Therefore, satiety is increased and voluntary food intake is reduced [7]. However, increased insulin secretion, caused by foods with high GI, leads to postprandial hyperinsulinemia along with an increase in both hunger and voluntary food intake [7]. This suggests that a low-GI diet may provide some level of prevention against developing diabetes and obesity and for managing existing CVD.

Several international GI tables have been published, generally Australian, British, or Canadian in origin [8-10]. Currently, no published GI table is available for Emirati foods. Given this lack of information, it has always been a challenging task for dieticians in UAE to design meal plans and to improve advice for preventing and managing obesity and other chronic diseases. Therefore, the main objective of the present study is to provide this data on the nutritional composition, GI, and GL values of five selected traditional Emirati foods commonly consumed in UAE and to assess the effect of the nutritional composition on the GI and GL values of these foods.

\section{Methods}

Ethical approval for the study protocol was obtained from the Scientific Research Ethics Committee at UAE University (UAEU, Reference No: 516/09), and all subjects gave written informed consent to participate. The subjects were given full details of the study protocol with the opportunity to ask questions.
All subjects were recruited from UAEU for voluntary participation in the study. A number of different methods were used for recruitment: email circulation, posters displayed in different UAEU buildings, and word of mouth. Fifteen healthy female subjects aged between 18 and 25 years old were recruited. The subjects were excluded if they had a fasting blood glucose value $>7.0 \mathrm{mmol} / \mathrm{L}$. They were also asked to complete a health questionnaire before the study. The subjects were asked not to undertake vigorous activities on the day before the test, to avoid caffeine-containing drinks, and not to smoke for $24 \mathrm{~h}$ before the test; instructions concerning meals on the previous day were not provided, because the fat and carbohydrate content of the evening meal before GI testing does not influence blood glucose response [11].

\section{Anthropometric measurements}

Measurements of body size and body composition were all carried out in the Nutrition and Health Department laboratory at UAEU. All anthropometric measurements were taken after a 12-h fast (fasting stage) with the subjects wearing light clothes and no shoes. The measurements were made of height $(\mathrm{cm})$ using a stadiometer (Seca Ltd., Birmingham, UK) [12], waist circumference (WC; $\mathrm{cm}$ ) using a measuring tape and body weight $(\mathrm{kg})$, FM, and fat-free mass (FFM) using a Segmental Body Composition Analyzer (TBF-410 MA; Tanita Corp., Tokyo, Japan) [13]. BMI was calculated as the weight in kilograms divided by the square of the height in meters: BMI $=$ Weight $(\mathrm{kg}) /$ Height $^{2}\left(\mathrm{~m}^{2}\right)$, using cut-off values for normal weight, overweight, and the various levels of obesity in adults from WHO [14].

\section{Test foods}

The present study is part of an ongoing research project funded by the Emirates Foundation to assess the GI of 20 traditional foods commonly consumed in UAE. The five test foods were selected as highly reproducible and the most acceptable to all subjects. The selected foods were obtained from three popular restaurants in $\mathrm{Al}$ Ain that specialized in Emirati foods and could prepare the foods from standardized recipes. The selected test foods were sweet dishes: Gurus, Saqo, and Assidah, and main dishes: Threed chicken and Marqoqa (Table 1).

Table 1 Main ingredients used in the preparation of five traditional foods commonly consumed in UAE

\begin{tabular}{ll}
\hline Local name (description) & Ingredients \\
\hline Gurus (fried bread) & Wheat flour, vegetable oil, egg, sugar, salt, and water \\
Assidah (flour with ghee) & Wheat flour, sugar, ghee, salt, and water \\
Saqo (saqo seeds with ghee) & Saqo seeds, sugar, ghee, saffron, and water \\
Marqoga (bread with chicken stew) & Wheat flour, chicken, potatoes, onions, tomatoes, carrots, tomato paste, vegetable oil, garlic, spices, and water \\
Threed chicken (bread with chicken stew) & Wheat flour, chicken, potatoes, onions, tomatoes, zucchini, tomato paste, vegetable oil, spices, and water \\
\hline
\end{tabular}




\section{Chemical analyses}

Proximate analysis for the test foods was carried out in the Nutrition and Health Department laboratory at UAEU. The proximate analysis was done for each test food using the standard method of the Association of Official Analytical Chemists [15]. Each test food was analyzed three times on separate occasions at the beginning, middle, and end of the month; this was done to ensure that the restaurants were consistent in using the food recipe. The test foods were also separately homogenized and prepared in triplicate, and average results were determined for the proximate analyses of moisture, protein, fat, fiber, and ash content using the following methods.

The moisture content was determined using the forced air draft oven method by drying $1 \mathrm{~g}$ of sample at $105^{\circ} \mathrm{C}$ for $16 \mathrm{~h}$ in an air oven [15]; the ash content was determined by adding $1 \mathrm{~g}$ of sample to a crucible and ashing in a muffle furnace maintained at $500^{\circ} \mathrm{C}$ for $4 \mathrm{~h}$ [15]; the total protein was determined by the Kjeldahl method (2300 Kjeltec Analyzer Unit, Foss A/S, Hillerød, Denmark) and was calculated using the general factor 6.25 [15]; the fat content was determined by extraction with light petroleum ether and then the solvent was removed by distillation using a Soxhlet extraction equipment. The residue was dried at $103^{\circ} \mathrm{C}$ and the fat content was determined gravimetrically [15]; the fiber content was determined using sequential extraction of food samples with sulfuric acid and sodium hydroxide. The insoluble residue collected by filtration was dried, weighed, and ashed [15]. After these analyses, the carbohydrate content was estimated by subtraction of the mean percentage values of moisture, ash, protein, lipids, and dietary fiber from 100 [16]. The energy content was calculated by multiplying the amounts of protein, fat, and carbohydrates by factors of 4,9 , and 4 , respectively [17].

\section{Procedures for determining Gl}

The GI value of the test foods was determined by feeding them to the 15 healthy subjects. The study of the subjects started in the morning after a 12-h overnight fast. A fasting blood sample was taken at $0 \mathrm{~min}$; then immediately after this, the subjects consumed a standard or test food within $15 \mathrm{~min}$ in a comfortable place. All the test and standard foods were served with $200 \mathrm{~mL}$ water. Further blood samples were taken at 15, 30, 45, 60,90 , and $120 \mathrm{~min}$ after starting to eat.

The standard food provided was $50 \mathrm{~g}$ glucose powder (glucose dextrose monohydrate) dissolved in $200 \mathrm{~mL}$ water. This was consumed by the subject on two separate occasions and the other test foods were consumed only once in a random order, with a gap of at least a day between measurements to minimize any carry-over effects.
Blood was obtained from a finger prick using the Onetouch $^{\odot}$ UltraSoft Lancing Device (One-Touch ${ }^{\circ}$ Ultra $^{\circ}$, LifeScan, Livingstone, UK). The third finger on the left hand was used for all finger-prick blood samples. Before the finger prick, the subjects were encouraged to warm their hands to increase blood flow. The fingers were not squeezed to extract blood from the fingertip as squeezing may dilute the blood with plasma. A $0.6 \mu \mathrm{L}$ blood sample was used to measure the blood glucose using an automatic analyzer (One-Touch ${ }^{\circ}$ Ultra $^{\circ} 2$, LifeScan). The blood glucose meters were calibrated daily using control solutions from the manufacturer.

\section{Calculation of GI and GL}

The incremental area under the blood glucose response curve (IAUC), ignoring the area beneath the baseline, was calculated geometrically [18]. The IAUC for each test meal eaten by each subject was expressed as a percentage of the mean IAUC for the standard food eaten by the same subject as follows: GI $=$ (IAUC for the test food containing $50 \mathrm{~g}$ of available carbohydrate/IAUC of a standard food with an equal carbohydrates portion) $x$ 100. The GI of each tested food was taken as the mean value from the whole group of subjects [18-20]. The glycemic load (GL) was calculated according to the formula $[18,20]: \mathrm{GL}=(\mathrm{GI}$ of test food $\times$ amount of carbohydrate in a serving of test food $(\mathrm{g})) / 100$.

\section{The power of analysis}

A sample size of 15 was considered sufficient with $90 \%$ power and an alpha of 0.05 using a paired $t$-test statistic considering an effect size of 1.4 for glucose response over time and 1.6 for glucose response between the foods.

\section{Statistical analysis}

Statistical analysis was performed using the statistical package SPSS 20.0 (Statistical Package for the Social Sciences, IBM, Cary, NC, USA). The Kruskal-Wallis test was used to compare the medians of measurements of nutrients for the types of food because the measurements did not satisfy the normality assumption of ANOVA. The paired $t$-test was used to compare the mean of the IAUC of the standard food with each of the test foods. Statistical significance was set at $P<0.05$.

\section{Results}

\section{Physical characteristics}

The physical characteristics of the study subjects were as follows: mean weight $54.2 \pm 4.7 \mathrm{~kg}$, BMI $21.2 \pm 2.1 \mathrm{~kg} / \mathrm{m}^{2}$, and WC $64.8 \pm 4.7 \mathrm{~cm}$ (Table 2). The subjects for the present study were selected according to specific criteria. The reason for setting these inclusion criteria was to assess the GI value of selected commonly consumed 
Table 2 Physical characteristics of the study population (mean \pm SD, $n=15$ )

\begin{tabular}{ll}
\hline Characteristics & Mean \pm SD \\
\hline Age (years) & $23.3 \pm 2.1$ \\
Height $(\mathrm{m})$ & $1.60 \pm 0.04$ \\
Weight $(\mathrm{kg})$ & $54.2 \pm 4.7$ \\
BMI $\left(\mathrm{kg} / \mathrm{m}^{2}\right)$ & $21.2 \pm 2.1$ \\
WC $(\mathrm{cm})$ & $64.8 \pm 4.7$ \\
FM $(\%)$ & $23.0 \pm 4.0$ \\
FM (kg) & $12.5 \pm 2.7$ \\
FFM (\%) & $0.8 \pm 0.1$ \\
FFM (kg) & $41.6 \pm 3.6$ \\
\hline BMI body mass index, WC waist circumference, FM fat mass, FFM fat free mass.
\end{tabular}

traditional foods by subjects with a normal BMI with respect to their age, weight, and height. Additionally, other parameters, WC, FM, and FFM, were also taken into consideration when selecting subjects within the normal range.

\section{Chemical analyses of test foods}

The first stage involved in the calculation of the GI value was the proximate composition of the selected foods. Data on the proximate analysis per $100 \mathrm{~g}$ of each test food are given in Table 3 . There were considerable variations in the nutritional composition of the analyzed foods, owing to the different ingredients and preparation methods. The moisture content ranged from $23.8 \mathrm{~g}$ for test food 1 (Gurus) to $77.1 \mathrm{~g}$ for test food 2 (Assidah). The protein content was lowest in test food 3 (Saqo) at $0.80 \mathrm{~g}$ and highest in test food 1 (Gurus) at $8.7 \mathrm{~g}$.

The preparation of test food 1 (Gurus) involved frying bread in oil, thus giving it a high-fat profile $(7.7 \mathrm{~g})$ as illustrated in Table 3. Fiber analysis showed that test food 1 (Gurus) had the highest fiber level at $4.1 \mathrm{~g}$, whereas test food 3 (Saqo) had the lowest level at $0.30 \mathrm{~g}$.

The preparation methods for the test foods were based on different ingredients, which can be related to the carbohydrate content and energy value of each food. For example, test food 5 (Threed chicken) had a lower carbohydrate content $(12.2 \mathrm{~g})$ than test food 1 (Gurus; $54.4 \mathrm{~g}$ ). This large difference of $42.2 \mathrm{~g}$ was because of the ingredients of test food 1 (Gurus), which comprised mainly wheat flour, vegetable oil, salt, and water, after which frying in oil is required for the bread preparation. Thus, it had the highest energy value $(322.2 \mathrm{kcal})$ of the test foods. Test foods 4 (Marqoqa) and 1 (Gurus) had the highest ash contents of 1.2 and $1.0 \mathrm{~g}$, respectively.

\section{Portion sizes, Gl, and GL classification of test foods}

The GI test is based on $50 \mathrm{~g}$ in each test food of available carbohydrate, defined as the total carbohydrate minus the dietary fiber. Therefore, the portion size of each test food, shown in Table 4, could vary according to the quantity of carbohydrate available in that food. The standard food (glucose) was tested using an equivalent amount of carbohydrate $(50 \mathrm{~g})$. The portion sizes of the test foods ranged from $91.8 \mathrm{~g}$ for test food 1 (Gurus) to $406.8 \mathrm{~g}$ for test food 5 (Threed chicken).

Table 4 also shows the GI and GL values and classification of the five test foods. These results showed that the GI values for the five test foods ranged from 71.7 to 99.4, which classified them all as high-GI foods. Test foods 1 (Gurus) and 5 (Threed chicken) had the lowest GI value (71.7 and 71.9, respectively), whereas test foods 2 (Assidah) and 3 (Saqo) had the highest GI value (99.2 and 99.4, respectively). The results also showed that the GL values for the five test foods ranged from 35.8 to 49.7, falling into the high-GL category. Test foods 3 (Saqo) and 2 (Assidah) had the highest GL values of 49.7 and 49.6, respectively, which corresponded with their highGI values. Similar patterns were observed for test foods 1 (Gurus) and 5 (Threed chicken), which had lower GI values and also lower GL values of 35.8 and 35.9, respectively.

\section{Glycemic response of food}

The mean incremental areas under the glycemic response curves for the standard and test foods are shown in Figure 1.

Table 3 Proximate analysis (three analyses/food) of UAE five traditional foods (100 g); (mean \pm SD)

\begin{tabular}{|c|c|c|c|c|c|c|}
\hline & $\begin{array}{l}\text { Test food } 1 \\
\text { Gurus }\end{array}$ & $\begin{array}{c}\text { Test food } 2 \\
\text { Assidah }\end{array}$ & $\begin{array}{c}\text { Test food } 3 \\
\text { Saqo }\end{array}$ & $\begin{array}{c}\text { Test food } 4 \\
\text { Marqoqa }\end{array}$ & $\begin{array}{c}\text { Test food } 5 \\
\text { Threed chicken }\end{array}$ & $P$ value ${ }^{*}$ \\
\hline Protein (g) & $8.76 \pm 0.16$ & $0.99 \pm 0.05$ & $0.80 \pm 1.09$ & $5.89 \pm 0.89$ & $7.81 \pm 1.76$ & 0.012 \\
\hline Fat (g) & $7.71 \pm 0.90$ & $0.04 \pm 0.05$ & $0.53 \pm 0.17$ & $2.16 \pm 1.24$ & $2.27 \pm 1.28$ & 0.014 \\
\hline Fiber (g) & $4.11 \pm 0.73$ & $0.67 \pm 0.34$ & $0.30 \pm 0.11$ & $3.24 \pm 4.30$ & $0.51 \pm 0.31$ & 0.034 \\
\hline Moisture (g) & $23.89 \pm 1.84$ & $77.17 \pm 1.30$ & $74.91 \pm 2.69$ & $74.18 \pm 1.66$ & $76.48 \pm 3.46$ & 0.017 \\
\hline Ash (g) & $1.07 \pm 0.21$ & $0.05 \pm 0.01$ & $0.04 \pm 0.01$ & $1.20 \pm 0.26$ & $0.64 \pm 0.04$ & 0.014 \\
\hline Carbohydrate (g) & $54.45 \pm 2.60$ & $21.08 \pm 1.14$ & $23.43 \pm 3.54$ & $13.32 \pm 4.48$ & $12.29 \pm 1.1$ & 0.014 \\
\hline Energy (kcal) & $322.26 \pm 6.55$ & $88.65 \pm 4.74$ & $101.66 \pm 11.54$ & $96.31 \pm 15.50$ & $100.82 \pm 14.93$ & 0.025 \\
\hline
\end{tabular}

Data expressed as $100 \mathrm{~g}$ on a fresh weight basis.

${ }^{*} P<0.05$. 
Table $4 \mathrm{GI}$ and GL value and classification of five foods commonly consumed in the United Arab Emirates

\begin{tabular}{lcccccc}
\hline Test foods & Available CHO $\mathbf{( g )}$ & Portion size $\mathbf{( g )}$ & Gl value & Classification & GL value & Classification \\
\hline Test food 1 (Gurus) & 50 & 91.8 & 71.7 & High & 35.85 & High \\
Test food 2 (Assidah) & 50 & 237.1 & 99.2 & High & 49.6 & High \\
Test food 3 (Saqo) & 50 & 213.4 & 99.4 & High & 49.7 & High \\
Test food 4 (Marqoga) & 50 & 375.3 & 84.6 & High & 42.3 & High \\
Test food 5 (Threed chicken) & 50 & 406.8 & 71.9 & High & 35.95 & High \\
\hline
\end{tabular}

The differences in glucose response between the test foods were analyzed using a $t$-test. The incremental increase in blood glucose at 15 min was significantly different between test food 1 (Gurus) and the standard food $(P=0.017$; mean $=0.66$ and 1.12 , respectively); at $30 \mathrm{~min}$, it was significantly different between test foods 1 (Gurus) and 4 (Marqoqa) $(P=0.001$ and 0.027; mean $=$ 1.42 and 0.85 , respectively). At $45 \mathrm{~min}$, the significant differences were between test foods 1 (Gurus), 4 (Marqoqa), and 5 (Threed chicken $)(P<0.001,0.01$, and 0.01 ; mean $=$ $1.04,1.06$, and 0.67 , respectively). Test foods 4 (Marqoqa) and 5 (Threed chicken) showed a significant difference in incremental blood glucose at $60 \mathrm{~min}(P=0.02$ and 0.01 ; mean $=0.84$ and 0.80 , respectively); at $90 \mathrm{~min}$, test food 5 showed a significant difference compared with the standard food $(P=0.036$; mean $=0.41$ and 1.20 , respectively $)$. At $120 \mathrm{~min}$, there were no significant differences in the incremental blood glucose levels between any test foods $(P>0.05)$.

IAUC for the standard and test foods (mean \pm SD)

Table 5 shows the IAUC for the five test foods. Significant differences were found in the IAUC between the standard and test food 1 (Guru) and test food 5 (Threed chicken $)(P=0.001$ and $<0.001$, respectively).

\section{Discussion}

Although the glycemic response is easy to measure, it is complicated to identify the mechanism of the glycemic response of food in the body. In fact, GI does not just measure the carbohydrate absorption in the small intestine directly but also indicates the effect of other factors in the foods tested that can influence the rate of carbohydrate absorption in the small intestine [9,21]. Adding fat and protein to carbohydrate-containing foods has the potential to reduce the glycemic response and lower the overall GI [22,23]. The mechanisms by which these nutrients affect blood glucose concentration have been proposed in many studies: high levels of protein produces greater gastric inhibitory peptide (GIP) and insulin responses resulting in a lower postprandial glucose peak and a reduced glycemic response from high-GI foods [24], while higher levels of fat content has the potential to delay gastric emptying, thereby slowing digestion and the absorption of glucose [23]. Fat may also affect the interaction of plasma glucose, insulin, and GIP [25]. This

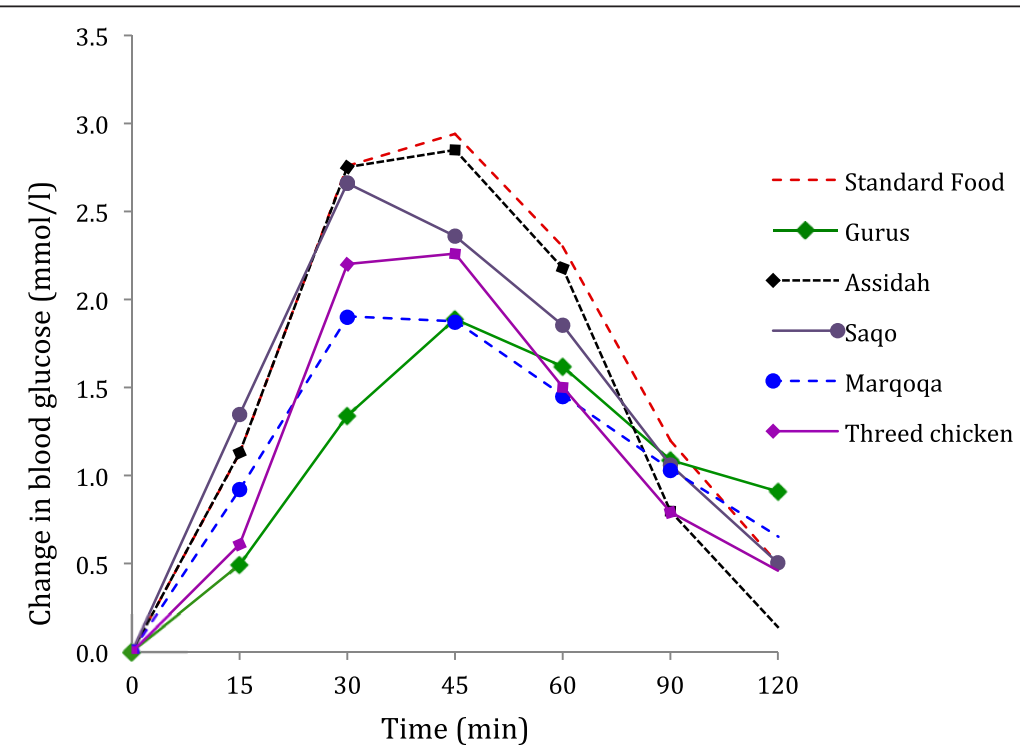

Figure 1 Incremental area under the blood glucose curves (IAUC) for the standard and the five test foods. 
Table 5 Incremental area under the blood glucose response curve (IAUC) for test foods

\begin{tabular}{lcc}
\hline Test foods & IAUC \pm SD & $P$ value \\
\hline Standard food & $202.57 \pm 34.56$ & \\
Test food 1 (Gurus) & $143.65 \pm 56.15$ & 0.001 \\
Test food 2 (Assidah) & $197.38 \pm 58.15$ & 0.745 \\
Test food 3 (Saqo) & $194.17 \pm 57.91$ & 0.654 \\
Test food 4 (Marqoga) & $162.64 \pm 74.22$ & 0.074 \\
Test food 5 (Threed chicken) & $142.41 \pm 32.37$ & 0.001 \\
\hline
\end{tabular}

could explain why test foods 5 (Threed chicken) and 1 (Gurus) with the high-protein content was observed to have a reduction of glycemic response in the IAUC compared with the standard food as well as having a GI value of 71.9 and 71.7 , which is close to the cut-off point (70) for the high-GI category.

In the present study, for Threed chicken, the blood glucose peak response from the IAUC was at 45 min which was significantly different from that for the standard food $(P=0.01)$. Owen and Wolever [25] studied the consumption of $50 \mathrm{~g}$ available carbohydrate from white bread with $0,5,10,20$, or $40 \mathrm{~g}$ fat of non-hydrogenatedfat margarine in healthy subjects. Their results showed that there was no significant IAUC for blood glucose reduction when white bread was consumed with 5,10 , or $20 \mathrm{~g}$ of fat, but a significant reduction in the IAUC for blood glucose (30\%) was observed when $40 \mathrm{~g}$ of fat was consumed with the white bread [26]. In contrast, a number of studies in foods commonly consumed in the UK [19] and in China [26] have found that the amount of protein or fat does not affect the glycemic value of foods. The present study found that there was a reduction in the IAUC for Threed chicken compared with the standard food where the amounts of protein may have affected the postprandial glycemic responses of that food [27]. It is assumed that the decrease in the postprandial glycemic response from the IAUC of Gurus was owed to its high-fat and fiber content (7.7 and $4.1 \mathrm{~g}$ ), which has an effect on the GI value of the food. A study by Livesey and Tagami [28] found that increasing the viscous soluble fiber consumption has a great effect on lowering the glycemic response but limits its palatability. The viscous fiber blend significantly reduced the glycemic index of food by $74 \%$ in healthy participants and by $63 \%$ in participants with diabetes [27]. Similarly, Jenkins et al. [29] showed a reduction in the IAUC of commonly consumed meals in healthy subjects when $5 \mathrm{~g}$ of novel viscous polysaccharide (NVP) was added.

All traditional foods tested contained white flour in their ingredients and different moisture contents and were prepared using different cooking time, which can all be related to explain the differences in the degree of starch gelatinization and consequently the GI values. Heat, moisture, and cooking method have been shown to be factors that can affect the GI of foods [30] and the GI of starchy food can be altered by the level of gelatinization [31].

Since all the test foods contained flour, we found that the effects of cooking method played a role in increasing the moisture content and therefore the GI value of foods. This was observed particularly in the preparation of Saqo, Assidah, and Marqoqa, which had the highest GI values (99.4, 99.2, and 84.6, respectively) compared with the other foods. The cooking process for Saqo involved mixing starchy seeds with sugar and fat and then boiling them slowly in water to form a viscous slurry, thus resulting in the maximum hydrolysis of the starch present in the Saqo seeds. These methods are the reasons behind the high glycemic response (IAUC) to Saqo. However, the preparation method for Marqoqa included a long cooking time (about $3 \mathrm{~h}$ ) for all the ingredients with water at a high temperature, which was then poured over the white bread. High temperature and increased cooking time in a large quantity of water were associated with increased starch gelatinization and degree of digestibility, as well as increased blood glucose levels [32]. Conversely, although Gurus had a high-fiber content, its GI value was still high (71.7). The increased GI value of Gurus could be because of the cooking method, which involved frying the ingredients with vegetable oil. Bahado-Singh et al. [33], found that fried sweet potato had an intermediate to moderately high GI value (63 \pm 2 to $77 \pm 4$ ), which was close to the GI value of Gurus found in the present study.

Different nutritional and physiological factors might have an effect on the blood glycemic response and the GI value of traditional foods. Included among these factors are the digestibility rate of the starch, the interactions of starch absorption with the amount of fiber, fat and protein present, and the cooking methods. In Threed chicken, the high-protein content led to a lower postprandial glucose peak and a decrease in glycemic response compared with other high-GI foods. Similar findings of a glycemic response reduction were observed in Gurus, with its high-fiber, fat, and protein content. The preparation method for Gurus, given its high-fat and protein content, led to delayed gastric emptying, thereby slowing down the rate of glucose digestion and absorption, while the traditional coo king procedures for Assidah, Saqo, and Marqoqa were associated with increases in the degree of starch gelatinization and consequently an increased GI value. The GI value was affected to varying degrees by the different preparation methods and ingredients of the five test foods. 


\section{Conclusions}

In the assessment of the nutrient composition and GI value of traditional foods, the present study can conclude that all the selected test foods, commonly consumed in UAE culture, had high GI values. These findings emphasize that the dietary habits and the consumption of traditional foods need to be assessed in connection with other factors with the evidence of the increasing prevalence of obesity in the UAE.

A limitation of this study was the effect of the different cooking methods used by the restaurants, which may have affected the GI values of these foods.

Since the traditional foods tested are frequently consumed by the Emirati, the authors of this study recommend the consumption of smaller portion sizes along with low-GI foods to overcome the high-GI level.

\section{Recommendation}

To completely address the objectives of this study, additional research should be performed using other traditional Emirati foods and obese and diabetic individuals as subjects to examine how this links to the increased prevalence of diabetes and obesity in the population. Studies on the chemical analysis and GI of other traditional foods are strongly recommended to be used as preliminary references for setting up a GI and GL database for traditional Emirati foods. The evaluation of an acceptable portion size for a low-GL diet is also needed. Moreover, preliminary studies to evaluate a low-GI diet using commonly consumed foods and the blood glucose and insulin responses among healthy subjects or diabetic patients are essential.

\section{Abbreviations}

BMI: Body mass index; CVD: Cardiovascular disease; DM: Diabetes mellitus; FM: Fat mass; FFM: Fat-free mass; Gl: Glycemic index; GIP: Gastric inhibitory peptide; GL: Glycemic load; IAUC: Incremental area under the blood glucose response curve; IDF: International Diabetes Federation; NVP: Novel viscous polysaccharide; UAE: United Arab Emirates; UAEU: United Arab Emirates University; WC: Waist circumference; WHO: World Health Organization.

\section{Competing interests}

The authors declare that they have no competing interests.

\section{Authors' contributions}

ASAD, LCL, and SAW conceived, designed, and supervised the experiments. ASAD and LCL wrote the paper. AKAM, FTAM, and MNM performed the experiments. ASAD, AKAM, and EMM analyzed the data. ASAD contributed reagents/materials/analysis tools. ASAD, $\mathrm{LCL}, \mathrm{AHJ}$, and AKAM contributed to the drafting of the manuscript. All authors read and approved the final manuscript

\section{Acknowledgements}

The authors would like to thank the Emirates Foundation for funding this project. We would also like to acknowledge the university students for their participation as subjects and the laboratory staff who performed the chemical analyses.

\section{Author details}

${ }^{1}$ Nutrition and Health Department, College of Food and Agriculture, United Arab Emirates University, Al Ain, United Arab Emirates. ${ }^{2}$ Department of Biotechnology, Faculty of Technology, Mahasarakham University, Mahasarakham 44150, Thailand. ${ }^{3}$ Department of Statistics, College of Business, United Arab Emirates University, Al Ain, United Arab Emirates.
Received: 30 June 2014 Accepted: 20 November 2014

Published: 21 January 2015

\section{References}

1. Steinberger J, Daniels SR: Obesity, insulin resistance, diabetes, and cardiovascular risk in children: an American Heart Association scientific statement from the Atherosclerosis, Hypertension, and Obesity in the Young Committee (Council on Cardiovascular Disease in the Young) and the Diabetes Committee (Council on Nutrition, Physical Activity, and Metabolism). Circulation 2003, 107(10):1448-1453.

2. Hensrud D: Dietary treatment and long-term weight loss and maintenance in type 2 diabetes. Obes Res 2001, 9(Suppl 4):348S-353S.

3. Li SC, Liu YH, Liu JF, Chang WH, Chen CM, Chen CY: Almond consumption improved glycemic control and lipid profiles in patients with type 2 diabetes mellitus. Metabolism 2011, 60(4):474-479.

4. International Diabetes Federation: IDF Diabetes Atlas. 6th edition. Brussels: International Diabetes Federation; 2013. [http://www.idf.org/diabetesatlas]. Accessed 19 February 2014

5. Hummasti S, Hotamisliqil GS: Endoplasmic reticulum stress and inflammation in obesity and diabetes. Circ Res 2010, 107(5):579-591.

6. Martin CL, Murphy SP, Au LMD: Compiling glycemic index and glycemic load values for addition to a food composition database. $J$ Food Compos Anal 2008, 21(6):469-473

7. Aller EEJG, Abete I, Astrup A, Martinez JA, Baak MA: Starches, sugars and obesity. Nutrients 2011, 3(3):341-369.

8. Foster-Powell K, Holt SH, Brand-Miller JC: International table of glycemic index and glycemic load values: 2002. Am J Clin Nutr 2002, 76:5-56.

9. Aston LM, Gambell JM, Lee DM, Bryant SP, Jebb SA: Determination of the glycaemic index of various staple carbohydrate-rich foods in the UK diet. Eur J Clin Nutr 2008, 62(2):279-285.

10. Foster-Powell K, Miler JB: International tables of glycemic index. Am J Clin Nutr 1995, 62(2):871S-890S.

11. Brown RC, Ning B, Williams S, Venn B, Green TJ: The macronutrient composition of the evening meal before glycemic index testing has no effect on glycemic response. FASEB J 2009, 23(Meeting Abstract Supplement):544.4.

12. Gibson RS: Principles of Nutritional Assessment. 2nd edition. New York: Oxford University Press; 2005

13. Chang C-I, Chen C-Y, Huang K-C, Wu C-H, Hsiung CA, Hsu C-C, Chen C-Y: Comparison of three BIA muscle indices for sarcopenia screening in old adults. Eur Geriatr Med 2013, 4(3):145-149.

14. World Health Organization (WHO): BMI Classification. Geneva: World Health Organization; 2006. [http://apps.who.int/bmi/index.jsp?introPage=intro_3. html]. Accessed 20 February 2014.

15. AOAC: Official Methods of Analyses 2003. Washington, DC: Association of Official Analytical Chemists; 2003.

16. Bouaziz MA, Besbes S, Blecker C, Attia H: Chemical composition and some functional properties of soluble fibro-protein extracts from Tunisian date palm seeds. Afr J Biotechnol 2013, 12(10):1121-1131.

17. Dashti BH, Al-Awadi F, Khalafawi MS, Al-Zenki S, Sawaya W: Nutrient contents of some traditional Kuwaiti dishes: proximate composition and phytate content. Food Chem 2001, 74(2):169-175.

18. Food and Agriculture Organization/World Health Organization: Carbohydrates in Human Nutrition 1998, Report of a Joint FAONHO Expert Consultation. Rome: FAO; 1998.

19. Henry CJ, Lightowler HJ, Strik CM, Renton H, Hails S: Glycaemic index and glycaemic load values of commercially available products in the UK. $\mathrm{Br} J$ Nutr 2005, 94(6):922-930

20. Kris Y, Lok RC, Chan D, Li L, Leung G, Woo J, Lightowler HJ, Henry CJ: Glycaemic index and glycaemic load values of a selection of popular foods consumed in Hong Kong. Br J Nutr 2010, 103:556-560.

21. Wolever TM: Carbohydrate and the regulation of blood glucose and metabolism. Nutr Rev 2003, 61(5 Pt 2):S40-S48.

22. Flint A, Moller BK, Raben A, Pedersen D, Tetens I, Holst JJ, Astrup A: The use of glycaemic index tables to predict glycaemic index of composite breakfast meals. Br J Nutr 2004, 91(6):979-989.

23. Henry CJ, Lightowler HJ, Kendall FL, Storey M: The impact of the addition of toppings/fillings on the glycaemic response to commonly consumed carbohydrate foods. Eur J Clin Nutr 2006, 60(6):763-769.

24. Hätönen KA, Virtamo J, Eriksson JG, Sinkko HK, Sundvall JE, Valsta LM: Protein and fat modify the glycaemic and insulinaemic responses to a mashed potato-based meal. Br J Nutr 2011, 106(2):248-253. 
25. Owen B, Wolever TM: Effect of fat on glycaemic responses in normal subjects: a dose-response study. Nutr Res 2003, 23(10):1341-1347.

26. Chen YJ, Sun FH, Wong SH, Huang YJ: Glycemic index and glycemic load of selected Chinese traditional foods. World J Gastroenterol 2010 16(12):1512-1517.

27. Jenkins AL, Jenkins DJ, Wolever TM, Rogovik AL, Jovanovski E, Bozikov V, Rahelić D, Vuksan V: Comparable postprandial glucose reductions with viscous fiber blend-enriched biscuits in healthy subjects and patients with diabetes mellitus: acute randomized controlled clinical trial. Croat Med J 2008, 49(6):772-782.

28. Livesey $\mathrm{G}$, Tagami H: Interventions to lower the glycemic response to carbohydrate foods with a low-viscosity fiber (resistant maltodextrin): meta-analysis of randomized controlled trials. Am J Clin Nutr 2009, 89(1):114-125.

29. Jenkins AL, Kacinik V, Lyon M, Wolever TM: Effect of adding the novel fiber, PGX ${ }^{\oplus}$, to commonly consumed foods on glycemic response, glycemic index and GRIP: a simple and effective strategy for reducing post prandial blood glucose levels-a randomized, controlled trial. Nutr $J$ 2010, 9:58.

30. Ek KL, Brand-Miller J, Copeland L: Glycemic effect of potatoes. Food Chem 2012, 133:1230-1240.

31. Juansang J, Puttanlek C, Rungsardthong V, Puncha-arnon S, Uttapap D: Effect of gelatinisation on slowly digestible starch and resistant starch of heat-moisture treated and chemically modified canna starches. Food Chem 2012, 131(2):500-507.

32. Lehmann U, Robin F: Slowly digestible starch - its structure and health implications: a review. Trends Food Sci Technol 2007, 18(7):346-355.

33. Bahado-Singh PS, Riley CK, Wheatley AO, Lowe HI: Relationship between processing method and the glycemic indices of ten sweet potato (Ipomoea batatas) cultivars commonly consumed in Jamaica. J Nutr Metab 2011, 584832:6.

doi:10.1186/2055-0928-1-4

Cite this article as: Al Dhaheri et al:: The effect of nutritional composition on the glycemic index and glycemic load values of selected Emirati foods. BMC Nutrition 2015 1:4.

\section{Submit your next manuscript to BioMed Central and take full advantage of:}

- Convenient online submission

- Thorough peer review

- No space constraints or color figure charges

- Immediate publication on acceptance

- Inclusion in PubMed, CAS, Scopus and Google Scholar

- Research which is freely available for redistribution 